\title{
Pharmacotherapy for bipolar disorder and concordance with treatment guidelines: survey of a general population sample referred to a tertiary care service
}

\author{
Sabrina Paterniti ${ }^{1,2^{*}}$ and Jean-Claude Bisserbe
}

\begin{abstract}
Background: Many new approaches have been adopted for the treatment of bipolar disorder (BD) in the past few years, which strived to produce more positive outcomes. To enhance the quality of care, several guideline recommendations have been developed. For study purposes, we monitored the prescription of psychotropic drugs administered to bipolar patients who had been referred to tertiary care services, and assessed the degree to which treatment met specific guidelines.

Methods: Between December 2006 and February 2009, we assessed 113 individuals suffering from BD who had been referred to the Royal Ottawa Mental Health Centre (ROMHC) Mood Disorders Program by physicians within the community, mostly general practitioners. The Structured Clinical Interview for DSM-IV-TR was used to assess diagnosis. The prescribed treatment was compared with specific Canadian guidelines (CANMAT, 2009). Univariate analyses and logistic regression were used to assess the contribution of demographic and clinical factors for concordance of treatment with guidelines.

Results: Thirty-two subjects had BD type I (BD-1), and 81 subjects had BD type II (BD-II). All subjects with BD-I, and 90\% of the BD-Il group were given at least one psychotropic treatment. Lithium was more often prescribed for subjects with BD-I (62\%) than those with BD-II (19\%). Antidepressants were the most frequently prescribed class of psychotropics. Sixty-eight percent of subjects received treatment concordant with guidelines by medication and dose. The presence of a current hypomanic episode was independently associated with poorer concordance to guidelines. In more than half the cases, the inappropriate use of antidepressants was at the origin of the non concordance of treatment with respect to guidelines. Absence of psychotropic treatment in bipolar II patients and inadequate dosage of mood stabilizers were the two other main causes of non concordance with guidelines.
\end{abstract}

Conclusions: The factors related to treatment not concordant with guidelines should be further explored to determine appropriate strategies in implementing the use of guidelines in clinical practice.

Keywords: Bipolar disorder, Pharmacotherapy, Treatment, Guidelines

\section{Background}

Bipolar disorder (BD) is a chronic disease with high risk of relapse. This disease also results in a high rate of suicidal mortality [1]. Many treatments have been made available in recent years to manage $\mathrm{BD}$ and to enhance positive outcome. To improve the quality of care, several guidelines have been developed with the help of evidence-based medicine and expert consensus meetings [2-9]. Given the

\footnotetext{
* Correspondence: Sabrina.Paterniti@theroyal.ca

${ }^{1}$ Department of Psychiatry, University of Ottawa, Ottawa, ON, Canada

${ }^{2}$ Royal Ottawa Mental Health Centre, 1145 Carling Avenue, Ottawa, Ontario
} K1Z 7K4, Canada rapid growth in the number of available medications, some of these guidelines have been updated [10-14]. The first guidelines which were published in 1997 by the The Canadian Network for Mood and Anxiety Treatments (CANMAT) [15] were updated in 2005 [16]. This update resulted in major modifications in its recommendations while projecting integrated elements of efficacy, effectiveness, and side effects. Further updates appeared in 2007 and $2009[17,18]$. CANMAT guidelines pointed out specific recommendations for bipolar II disorder (BD-II), which was neglected by most of the previous guidelines.

\section{Biomed Central}


Two studies from the Texas Medication Algorithm Project underline the importance of enhanced adherence to clinical guidelines which can effectively improve the outcome of bipolar patients. Suppes et al. [19] assessed 141 bipolar patients treated in clinics where treatment guidelines were actively implemented in meetings with clinicians and in psychoeducational interventions with patients and families. They compared their outcome with that of 126 patients treated in a standard "as usual" protocol. The first group of patients showed greater sustained improvement at the initial and later stages with respect to overall severity of psychiatric symptoms, as well as in manic symptoms. For the same group of 141 bipolar patients, stricter adherence to treatment guideline recommendations was associated with greater reductions in depressive symptoms and overall psychiatric symptoms over time [20].

Despite the recent emphasis on evidence-based practice, guideline recommendations are not always implemented. Perlis [21] found that $34 \%$ of psychiatrists reported not having recourse to guidelines on a regular basis to treat $\mathrm{BD}$, where only a very small percentage identified guidelines as their primary source of information. Similar results were obtained in two other studies conducted in France and Serbia, where $40 \%$ and $34 \%$ of psychiatrists, respectively, had claimed non-use of guidelines in the management of $\mathrm{BD}$ in daily practice $[22,23]$.

The treatment of bipolar patients in concordance with guidelines varies widely throughout the studies, as shown in Table 1. Except for the low percentages found in three studies [24-26], concordance percentages ranged from $50 \%$ to $80 \%$. Smith et al. [27] found that concordance of treatment was $52 \%$ in a naturalistic setting, with a percentage increasing to $75 \%$ after a one-year psychoeducational intervention aimed at implementing the guidelines. Bauer et al. [28] found a concordance of $50-60 \%$ at the index hospitalization with respect to 306 participants monitored through a collaborative care model; there was, however, a marked decrease after 2 years. Dennehy et al. [29] found high percentages of concordance with treatment guidelines among psychiatrists who had participated in extensive training based on published clinical practice guidelines.

Some factors were linked to better concordance with guidelines. Manic patients were more likely to receive concordant treatment than patients suffering from depressive or mixed episodes [33]. The presence of psychotic features was related to higher percentages of concordance with treatment guidelines [24,26]. Treatment setting influenced concordance to treatment guidelines, with in-patients more frequently receiving adequate treatment than out-patients [25,34]. Patients diagnosed with anxiety or depressive disorder before being diagnosed with BD were less likely to receive antimanic medications and more likely to receive antidepressants without any antimanic treatment [34]. In the STEP-BD study, earlier age at onset and administration of adequate pharmacotherapy at entry predicted those more likely to receive guideline-concordant care during new-onset mood episodes [29]. In the same STEP-BD study [31], bipolar I patients were more likely to receive adequate treatment as opposed to bipolar II patients. Arvilommi et al. [25] found that with the lack of clinical diagnosis of $\mathrm{BD}$ at entry, rapid cycling, polyphasic index episode, as well as depressive index phase, were

Table 1 Studies of guideline concordance in bipolar disorder

\begin{tabular}{|c|c|c|c|c|}
\hline & Population & $\mathbf{N}$ & Guidelines & $\%$ Concordance \\
\hline Unutzer et al. 2000 [30] & Out-patients & $1246 \mathrm{BD}$ & Expert consensus panel & $83 \%$ \\
\hline Lim et al. 2001 [24] & In-patients & $1421 \mathrm{BDI}$ & Expert consensus panel & $\begin{array}{l}\text { Manic with psychotic features: } \\
\text { 38\% without: } 16 \% \text {; Depressive with } \\
\text { psychotic features: } 31 \% \text {; without: } 17 \%\end{array}$ \\
\hline Simon et al. 2004 [31] & Out-patients & $665 \mathrm{BDI}+239 \mathrm{BDI}$ & Several guidelines & BDI: 65.4\% BDII: 52.7\% \\
\hline Kilbourne et al. 2005 [32] & In- and out-patients & $2316 \mathrm{BDI}$ & $\begin{array}{l}\text { APA and Department of } \\
\text { Veterans Affairs }\end{array}$ & $\begin{array}{l}\text { Bipolar specific MS: } 74.6 \% \text { Any MS or } \\
\text { neuroleptics second generation: } 84.4 \%\end{array}$ \\
\hline Farrelly et al. 2006 [33] & Out-patients & $\begin{array}{l}224 \text { mood episodes in } \\
84 \mathrm{BD} \mathrm{I} \text { and II }\end{array}$ & $\begin{array}{l}\text { British Association for } \\
\text { Psychopharmacology }\end{array}$ & Manic: 81\% Depressive: 64\% Mixed: 62\% \\
\hline Dennehy et al. 2007 [29] & Out-patients & 469 BDI 198 BDII & Several guidelines & $\begin{array}{l}\text { Depressive: } 83.4 \% \text { Hypomanic/manic: } \\
\text { 81.9\% Mixed: } 81.8 \%\end{array}$ \\
\hline Bush et al. 2007 [34] & In- and out-patients & $2644 \mathrm{BDI}$ & Several guidelines & $67 \%$ \\
\hline Arvilommi et al. 2007 [25] & In- and out-patients & $\mathrm{BDI}-90 \mathrm{BD} \|-101$ & Several guidelines & BDI: 55.6\% BDII: 30.7\% \\
\hline Smith et al. 2008 [27] & In-patients & $23 \mathrm{BD}$ & Expert consensus panel & $\begin{array}{l}52 \% \text { in naturalistic settings, increased } \\
\text { to } 75 \% \text { after intervention }\end{array}$ \\
\hline Bauer et al. 2009 [28] & & $306(87 \%$ BDI) & $\begin{array}{l}\text { Department of Veterans } \\
\text { Affairs }\end{array}$ & $\begin{array}{l}50 \%-60 \% \text { at index hospitalization in } \\
\text { collaborative model; declined to } \\
30 \%-40 \% \text { after two years }\end{array}$ \\
\hline Altinbas et al. 2011 [26] & Out-patients & $\begin{array}{l}263 \text { depressive episodes } \\
\text { in } 142 \text { patients ( } 131 \mathrm{BDI})\end{array}$ & $\begin{array}{l}\text { Turkish Psychiatric Association } \\
\text { Guidelines for Bipolar Disorder }\end{array}$ & $\begin{array}{l}\text { Severity of the episode: Mild: } 29 . \% \text {; } \\
\text { Moderate or severe without psychosis: } \\
27.4 \% \text {; severe with psychos: } 87.5 \%\end{array}$ \\
\hline
\end{tabular}


independently associated with inadequate treatment. In a study assessing the treatment of veterans suffering from $\mathrm{BD}$ [32], race was not an associative factor in the administration of mood stabilizers.

To our knowledge, there has never been a study conducted on concordant treatment of bipolar patients in keeping with the CANMAT guidelines in Canada. The first object of our study was to examine the administration of psychotropic drugs among subjects diagnosed with BD and who had been referred to tertiary care services. The second objective was to assess concordance of prescribed treatments with Canadian guidelines. The third objective was to identify the clinical factors linked to poorer concordance of treatment with CANMAT guidelines.

\section{Methods}

\section{Sample}

The study "Prevalence, comorbidity and psychosocial risk factors: recurrent unipolar depression and bipolar disorder" was realized in the context of the Assessment and Treatment Clinic (ATC), an out-patient service established in 2006 within the framework of the Royal Ottawa Mental Health Centre (ROMHC) Mood Disorders Program. The ROMHC Mood Disorders Program provides specialized tertiary care service to all citizens of Ottawa, Ontario (estimated population in 2009: 885,715 inhabitants). It targets the population of high-risk mood disorder patients, namely, individuals with serious, complex, and/or rare mental disorders, who present multiple and complex needs, and whose treatment requirements cannot be met in the first line or at the more intensive levels of service. As such, these patients require more intensive and prolonged care resources. The study protocol was approved by the Research Ethics Board of ROMHC (Reference: REB\#200622). A written informed consent was obtained from participants, where the rational of the study was explained and the participants gave consent to publish the results of the study, but kept their identity confidential.

The selection of the cases to be assessed by the ATC was as follows. A nurse examined all the referrals from community doctors (mostly family physicians) to the mood disorders program and chose the referrals which were the most likely to satisfy the criteria for the program, that is, subjects suffering from primary recurrent or chronic unipolar major depressive disorder or $\mathrm{BD}$, were resistance to treatment, or severity required the intervention of the outpatient multidisciplinary team. About 20\% of all referrals were included and assessed by the ATC team through a diagnostic and clinical assessment, so a standardized diagnosis was available only for these patients. The psychiatrists of the program assessed the remaining cases, making recommendations for treatment or following the patients as appropriate. From December 2006 to February 2009, the ATC assessed 409 subjects, who were referred to the program by physicians within the community; mostly family physicians. Of these subjects, 113 (39 men and 74 women) presented with primary diagnosis of BD type I or II.

\section{Diagnostic and clinical assessment}

During the course of the initial visit, subjects underwent clinical interviews with a nurse, a social worker, an occupational therapist, a psychiatrist and a psychologist. Collection of information took on average 3 to 5 hours.

The Structured Clinical Interview for DSM-IV-TR (SCID) [35] was used to assess diagnosis on Axis I. The SCID screen was administered to all patients which included Mood and PTSD modules completed for every patient. Where anxiety, psychotic, or eating disorder was indicated based on SCID screening, these modules were administered as well. Substance abuse and dependence were flagged based on the chart review and the patient's report during the interdisciplinary assessment. The correspondent module was administered where indicated.

In cases where a diagnosis of $\mathrm{BD}$ proved inconclusive with the use of SCID-I ("rule out diagnoses"), all efforts were made to produce a valid diagnosis, by consulting the charts and/or interviewing the treating psychiatrist. The psychotropic medications that were prescribed and their dosages were recorded by a nurse. The lithium levels were measured in the following month after the first assessment. A history of previous hospitalizations was also systematically collected by a nurse.

\section{Criteria: adherence to treatment guidelines}

The CANMAT guidelines published in 2009 [18] were considered for purposes of evaluating treatment concordant with guidelines. CANMAT guidelines include first, second, and third line recommendations, where second and third line recommendations should be used when the first line are not effective, or not tolerated, or not indicated for other reasons. A systematic longitudinal pharmacological history of every patient was not available, so we could not verify if patients treated with second or third line treatments had already been prescribed with a treatment following a first line recommendation. However, our sample included patients referred to a tertiary care structure and the selection process of the sample included the criteria of having a resistant-to-treatment, or chronic, severe and highly recurrent disorder. In these cases, it is likely that the patients had already been prescribed with at least a first line treatment. For this reason, we considered second and third line treatments as concordant to guidelines.

Using the Structured Clinical Interview for DSM-IV (SCID) [35], we identified the nature of a given mood episode present in any month preceding the assessment ("current episode"). For cases exhibiting a current depressive episode, treatment was compared with recommendations 
for "acute bipolar depression" for BD type I (BD-I), as indicated in the Table four point three of the above publication [18] and BD-II (Table seven point two) [18]. For cases of hypomania, treatment was compared with recommendations for "acute mania" (Table three point three) [18]; otherwise, treatment was compared with recommendations for "maintenance treatment" for BD-I (Table five point five) and BD-II (7.4) [18]. No cases of acute mania were described among bipolar I patients at the moment of assessment.

Prescriptions for lithium, anticonvulsants, atypical antipsychotics, and antidepressants were considered for purposes of assessing prescribed treatments as concordant with the CANMAT guidelines, whether they were associated or not with benzodiazepines, zopiclone, or first generation neuroleptics. Although CANMAT guidelines do not explicitly specify the dose ranges for the recommended treatments, the recommendations are mainly based on clinical trials. Based on the results of these trials, we considered the following dosages to define a treatment as being in the "therapeutic range", so following the CANMAT recommendations: lithium blood levels $\geq 0.5 \mathrm{mEq} / \mathrm{L}$; valproate $\geq 750 \mathrm{mg}$ daily; carbamazepine $\geq 600 \mathrm{mg}$ daily; lamotrigine $\geq 50 \mathrm{mg}$ daily; olanzapine $\geq 5 \mathrm{mg}$ daily; risperidone $\geq 2 \mathrm{mg}$ daily; quetiapine $\geq 150 \mathrm{mg}$ daily.

The following exceptions were made: 1 ) trazodone at low dosage ( $\leq 50 \mathrm{mg}$ ) was not considered as "antidepressant", given its use as a hypnotic; 2) amitryptyline at low dosage (<50 mg) was not considered an antidepressant, given its use as an anti-pain or hypnotic under low dosage. "Polypharmacy" was defined as the association of more than one mood stabilizer, atypical antipsychotic and antidepressant, where at least one of the prescribed treatments met the CANMAT recommendations, though in combinations not specifically recommended by the guidelines. The classification "doesn't follow the guidelines" refers to patients not receiving any treatment included in the CANMAT recommendations.

\section{Data analysis}

Data was analyzed using SPSS 19.0 statistical package (PASW, Chicago, IL). Pearson $\chi^{2}$ test and t-tests were used where appropriate. Bonferroni corrections were used in the analyses. We considered the following analyses: 1) in descriptive statistics, we compared the proportions of subjects taking at least one of the different classes of psychotropics at any dosage (lithium, anticonvulsants, antidepressants, benzodiazepines, neuroleptics, at least one psychotropic drug) by type of bipolar disorder (BD-I or BD-II) and nature of the mood episode (hypomanic, depressive, euthymia). Two-tailed tests were considered as significant when $\mathrm{p}<0.001$. 2) We then compared the proportions of subjects taking at least one mood stabilizer or atypical antipsychotic with a dosage in the therapeutic range, by type of $\mathrm{BD}$ and nature of the mood episode. Two-tailed tests were considered as significant when $p<0.001$. 3) Finally, we compared the proportions of patients prescribed with guidelineconcordant treatment for the following predictors: sex; age; previous hospitalizations; type of $\mathrm{BD}$; nature of the current mood episode; comorbid anxiety disorder (current); comorbid substance use disorder (current); age at onset of the mood disorder. Two-tailed tests were considered as significant when $\mathrm{p}<0.006$. A logistic regression model was used to predict the independent likelihood of receiving treatment not concordant with guidelines.

\section{Results}

\section{Characteristics of the sample}

Sampling consisted of 32 patients diagnosed with BD- I, and 81 with BD-II. Sex and age were similar for both samples: two-thirds being female $(\mathrm{N}=74,65.5 \%)$; average age (SD) being 38.7 (11.2).

\section{Prevalence of psychotropic prescriptions by type of BD}

All bipolar I patients and 90\% of bipolar II patients were administered at least one psychotropic drug. Table 2 shows the number of patients receiving specific psychotropics, at any dosage. Statistical comparisons between BD-I and II were performed for classes of psychotropics only. Lithium was prescribed for one-third of the sample, more frequently in BD-I than BD-II. Among patients prescribed with lithium, a similar percentage of bipolar I and II patients were prescribed an adequate dosage, with serum levels $\geq 0.5 \mathrm{mEq} / \mathrm{L}$ (BD-I: $\mathrm{N}=16$ (80\%); BD-II: $\mathrm{N}=12$ $(80 \%)$. The median value of lithium serum levels were 0.59 and 0.79 in BD-I and II, respectively.

Anticonvulsants were prescribed for approximately $40 \%$ of the sample; more than $60 \%$ of bipolar patients were prescribed antidepressants. Second generation neuroleptics were prescribed much more frequently than first generation. Prescriptions for anticonvulsants, antidepressants, benzodiazepines and neuroleptics were not significantly different in the two types of $\mathrm{BD}$. Bipolar I patients were more likely be prescribed with at least one mood stabilizer or atypical antipsychotic at therapeutic range than bipolar II patients (BD-I: $84 \%$ vs BD-II: $49 \%, \chi^{2}=11.6, \mathrm{df}=1, \mathrm{p}<0.001$ ).

Our sample included only a minority of patients treated with one single mood stabilizer within monotherapy (lithium, lamotrigine, valproate, or carbamazepine), without being prescribed any antidepressants or second generation antipsychotics (bipolar I patients: $\mathrm{N}=11$ (34\%); bipolar II patients: $\mathrm{N}=12(15 \%)$.

\section{Psychotropic medications administered by nature of mood episodes}

No significant differences were found in the prescriptions by the nature of the mood episode, although there was a trend for subjects with a current depressive episode to be prescribed antidepressants more frequently 
Table 2 Psychotropic treatment by type of bipolar disorder among patients attending an out-patient tertiary care service

\begin{tabular}{|c|c|c|c|c|}
\hline & $\begin{array}{c}\text { Bipolar I disorder }(\mathrm{N}=32) \\
\mathrm{N}(\%)\end{array}$ & $\begin{array}{c}\text { Bipolar II disorder }(\mathrm{N}=81) \\
\mathrm{N}(\%)\end{array}$ & $\begin{array}{l}\text { Total } \\
\text { N (\%) }\end{array}$ & $\begin{array}{l}\text { Daily dosage min-max } \\
\text { Mg }\end{array}$ \\
\hline Lithium & $20(62.5)$ & $15(18.5)^{*}$ & $35(31.0)$ & $300-1950$ \\
\hline Anticonvulsants & $10(31.3)$ & $36(44.4)^{+}$ & $46(40.7)$ & \\
\hline Valproate & $3(9.4)$ & $14(17.3)$ & $17(15)$ & $250-2000$ \\
\hline Carbamazepine & $1(3.1)$ & 0 & $1(0.9)$ & 600 \\
\hline Lamotrigine & $6(18.8)$ & $13(16)$ & 19 (16.8) & $50-500$ \\
\hline Gabapentin & $1(3.1)$ & $6(7.4)$ & $7(6.2)$ & $300-1600$ \\
\hline Topiramate & $1(3.1)$ & $9(11.1)$ & $10(8.8)$ & $25-200$ \\
\hline Levetiracetam & 0 & $1(1.2)$ & $1(0.9)$ & 250 \\
\hline Antidepressants & $17(53.1)$ & $54(66.7)^{\dagger}$ & $71(62.8)$ & \\
\hline SSRIS & $7(21.9)$ & $27(33.3)$ & $34(30.1)$ & \\
\hline Citalopram & $4(12.5)$ & $10(12.3)$ & $14(12.4)$ & $20-80$ \\
\hline Escitalopram & $1(3.1)$ & $12(14.8)$ & $13(11.5)$ & $5-40$ \\
\hline Fluoxetine & $1(3.1)$ & $1(1.2)$ & $2(1.8)$ & 20 \\
\hline Fluvoxamine & $1(3.1)$ & 0 & $1(0.9)$ & 200 \\
\hline Paroxetine & 0 & $2(2.5)$ & $2(1.8)$ & $40-60$ \\
\hline Sertraline & 0 & $2(2.5)$ & $2(1.8)$ & $100-200$ \\
\hline SNRI & $9(28.1)$ & $13(16.0)$ & $22(19.5)$ & \\
\hline Duloxetine & 0 & $1(1.2)$ & $1(0.9)$ & 60 \\
\hline Venlafaxine & $9(28.1)$ & $12(14.8)$ & 21 (18.6) & $75-300$ \\
\hline Moclobemide & 0 & $1(1.2)$ & $1(0.9)$ & 600 \\
\hline Antidepressants Tricyclic & $1(3.1)$ & $5(6.2)$ & $6(5.3)$ & \\
\hline Amitriptyline & $1(3.1)$ & $4(4.9)$ & $5(4.4)$ & $10-100$ \\
\hline Trimipramine & 0 & $1(1.2)$ & $1(0.9)$ & 50 \\
\hline Other antidepressants & $6(18.8)$ & $27(33.3)$ & $33(29.2)$ & \\
\hline Bupropion & $2(6.3)$ & $13(16.0)$ & $15(13.3)$ & $100-450$ \\
\hline Mirtazapine & 0 & $4(4.9)$ & $4(3.5)$ & $7.5-60$ \\
\hline Trazodone & $5(15.6)$ & $13(16.0)$ & $18(15.9)$ & $50-200$ \\
\hline Anxiolytics benzodiazepines & $10(31.3)$ & $16(19.8)^{\dagger}$ & $26(23.0)$ & \\
\hline Neuroleptics & $18(56.3)$ & $33(40.7)^{\dagger}$ & $51(45.1)$ & \\
\hline Neuroleptics first generation & $2(6.3)$ & $4(4.9)$ & $6(5.3)$ & \\
\hline Methotrimeprazine & $1(3.1)$ & $4(4.9)$ & $5(4.4)$ & $10-125$ \\
\hline Trifluoperazine & $1(3.1)$ & 0 & $1(0.9)$ & 3 \\
\hline Neuroleptics second generation & $17(53.1)$ & $30(37.0)$ & $47(41.6)$ & \\
\hline Olanzapine & $7(21.9)$ & $6(7.4)$ & $13(11.5)$ & $2.5-20$ \\
\hline Quetiapine & $8(25.0)$ & $18(22.2)$ & $26(23.0)$ & $12.5-450$ \\
\hline Risperidone & $2(6.3)$ & $8(9.9)$ & $10(8.8)$ & $0.5-2.00$ \\
\hline Stimulants - methylphenidate & 0 & $1(1.2)$ & $1(0.9)$ & 5 \\
\hline Hypnotics - Zopiclone & 0 & $5(6.2)$ & $5(4.4)$ & $3.75-30$ \\
\hline No psychotropics & 0 & $8(90.0)$ & $8(7.0)$ & \\
\hline
\end{tabular}

${ }^{*} \mathrm{p}<0.001{ }^{+} \mathrm{NS}$.

than other subjects $\left(72 \%\right.$ vs. $50 \%$, respectively, $\chi^{2}=5.9$, $\mathrm{df}=1, \mathrm{p}<0.02)$ (Table 3). Especially noteworthy was the relatively frequent prescription of antidepressants to subjects suffering from current hypomanic episodes (43\% in BD-I and 56\% in BD-II).

\section{Prescriptions concordant with CANMAT guidelines}

Eight-four patients (74.3\%) were prescribed with at least one treatment congruent with CANMAT guidelines when considering only the type of the treatment. When we considered type and therapeutic dosage, the number decreased 
Table 3 Classes of psychotropic treatment by type of bipolar disorder and nature of current mood episode

\begin{tabular}{|c|c|c|c|c|c|c|}
\hline & \multicolumn{3}{|c|}{ Bipolar I disorder $(\mathrm{N}=32)$} & \multicolumn{3}{|c|}{ Bipolar II disorder $(\mathrm{N}=\mathbf{8 1})$} \\
\hline & Hypomania & Depression & Euthymia & Hypomania & Depression & Euthymia \\
\hline & $N=7$ & $N=18$ & $N=7$ & $N=18$ & $N=47$ & $N=16$ \\
\hline & N (\%) & N (\%) & $\mathrm{N}(\%)$ & N (\%) & N (\%) & N (\%) \\
\hline Lithium & $4(57.1)$ & $11(61.1)$ & $5(71.4)$ & $3(16.7)$ & $8(17.0)$ & $4(25.0)$ \\
\hline Anticonvulsants & $2(28.6)$ & $5(27.8)$ & $3(42.9)$ & $7(38.9)$ & $25(53.2)$ & $4(25.0)$ \\
\hline Antidepressants & $3(42.9)$ & $13(72.2)$ & $1(14.3)$ & $10(55.6)$ & $34(72.3)$ & $10(62.5)$ \\
\hline Neuroleptics & $3(42.9)$ & $11(61.1)$ & $4(57.1)$ & $7(38.9)$ & $20(42.6)$ & $6(37.5)$ \\
\hline First generation & 0 & $1(5.6)$ & $1(14.3)$ & $1(5.6)$ & $3(6.4)$ & 0 \\
\hline Second generation & $3(42.9)$ & $11(61.1)$ & $3(42.9)$ & $6(33.3)$ & $18(38.3)$ & $6(37.5)$ \\
\hline Benzodiazepines & 0 & $7(38.9)$ & $3(42.9)$ & $3(16.7)$ & $8(17.0)$ & $5(31.3)$ \\
\hline At least one MS or AAP in therapeutic range* & $7(100)$ & $15(83.3)$ & $5(71)$ & $8(44.4)$ & $26(55.3)$ & $6(37.5)$ \\
\hline At least one psychotropic drug & $7(100)$ & $18(100)$ & $7(100)$ & $16(88.9)$ & $44(93.6)$ & $13(81.3)$ \\
\hline
\end{tabular}

${ }^{*} \mathrm{MS}$ or AAP in therapeutic range: lithium serum levels $\geq 0.5 \mathrm{mEq} / \mathrm{L}$; valproate $\geq 750 \mathrm{mg}$ daily; carbamazepine $\geq 600 \mathrm{mg}$ daily; lamotrigine $\geq 50 \mathrm{mg}$ daily; olanzapine $\geq 5 \mathrm{mg}$ daily; risperidone $\geq 2 \mathrm{mg}$ daily; quetiapine $\geq 150 \mathrm{mg}$ daily.

to 77 (68.1\%) (Table 4). Among bipolar I patients, the number of patients prescribed with at least one treatment concordant with guidelines for both type and dosage was 24 (75\%); 4 (12\%) bipolar I patients were prescribed with at least one treatment concordant for type but not for dosage. The corresponding figures for BD-II were 53 (65.4\%) and 3 (4\%), respectively. Of the 47 bipolar II patients in a depressive phase, 12 patients were prescribed antidepressants within monotherapy, which is classified as a third line recommendation under the CANMAT guidelines.

The reasons for non-concordance with guidelines appeared to vary according to the nature of the episode (Table 5). A high percentage of subjects with current hypomanic episodes were prescribed with no treatment concordant with guidelines (17 out of 25 patients, $68 \%$ ); in 13 of these 17 cases, subjects were prescribed antidepressants. Ten bipolar II patients in a hypomanic phase were prescribed with antidepressants. Six of these patients had "mixed" depressive-hypomanic symptoms corresponding to a "dysphoric" state, and two patients presented rapid cycling. The remaining two patients had mild to moderate hypomanic symptoms. Among subjects for whom treatment non-concordant with guidelines was prescribed, a total of 11 patients were prescribed antidepressants without any mood stabilizer.

Factors associated with the prescription of at least one treatment concordant with guidelines by type and dosage of the medication

The associations between several clinical factors and treatment concordant with guidelines (Table 6) were studied. Univariate analyses showed that hypomanic patients presented poorer guideline concordance $(p<0.001)$. There was also a similar non significant trend for patients having had no previous hospitalizations $(\mathrm{p}<0.05)$ and presenting a current substance disorder $(\mathrm{p}<0.06)$.

To test the independent association of the same variables with a poorer concordance of treatment to guidelines, we performed a logistic regression, where concordant treatment with guidelines was the dependent variable $(0=$

Table 4 Treatment concordant with CANMAT guidelines by medication and dosage in bipolar patients, by type of disorder and by nature of current episode

\begin{tabular}{|c|c|c|c|c|c|c|c|}
\hline & \multicolumn{3}{|c|}{ Bipolar I disorder $(\mathrm{N}=32)$} & \multicolumn{3}{|c|}{ Bipolar II disorder $(\mathrm{N}=\mathbf{8 1})$} & \multirow[b]{2}{*}{$\begin{array}{c}\text { Total } \\
\mathrm{N}=113\end{array}$} \\
\hline & $\begin{array}{c}\text { Hypomania } \\
\mathrm{N}=7\end{array}$ & $\begin{array}{l}\text { Depression } \\
\qquad \mathrm{N}=18\end{array}$ & $\begin{array}{c}\text { Euthymia } \\
\qquad N=7\end{array}$ & $\begin{array}{c}\text { Hypomania } \\
\mathrm{N}=18\end{array}$ & $\begin{array}{l}\text { Depression } \\
\qquad N=47\end{array}$ & $\begin{array}{c}\text { Euthymia } \\
N=16\end{array}$ & \\
\hline Follows guidelines strictly & $4(57.1 \%)$ & $8(44.4 \%)$ & $4(57.1 \%)$ & $3(16.7 \%)$ & $29(61.7 \%)$ & $4(25.0 \%)$ & $52(46.0 \%)$ \\
\hline First line treatment & $4(57.1 \%)$ & $5(27.8 \%)$ & $3(42.9 \%)$ & $3(16.7 \%)$ & 0 & $1(6.3 \%)$ & $16(14.2 \%)$ \\
\hline Second line treatment & 0 & $1(5.6 \%)$ & $1(14.3 \%)$ & 0 & $14(29.8 \%)$ & $3(18.8 \%)$ & $19(16.8 \%)$ \\
\hline Third line treatment & 0 & $2(11.1 \%)$ & 0 & 0 & $15(31.9 \%)$ & 0 & $17(15.0 \%)$ \\
\hline $\begin{array}{l}\text { Polypharmacy with at least one treatment } \\
\text { recommended in guidelines }\end{array}$ & 0 & 7 (38.9\%) & $1(14.3 \%)$ & $1(5.6 \%)$ & $14(29.8 \%)$ & $2(12.5 \%)$ & $25(22.1 \%)$ \\
\hline No treatment following the guidelines & $3(42.9 \%)$ & $3(16.7 \%)$ & $2(28.6 \%)$ & $14(77.8 \%)$ & $4(8.5 \%)$ & $10(62.5 \%)$ & $36(31.9 \%)$ \\
\hline
\end{tabular}

*Treatment concordant for type and dosage of prescribed mood stabilizers. 
Table 5 Reasons for non-concordance of treatment with guidelines

\begin{tabular}{|c|c|c|c|c|c|c|c|}
\hline & \multicolumn{3}{|c|}{$\begin{array}{l}\text { Bipolar I disorder with } \\
\text { no treatment concordant } \\
\text { with guidelines }(\mathrm{N}=8)\end{array}$} & \multicolumn{3}{|c|}{$\begin{array}{l}\text { Bipolar II disorder with } \\
\text { no treatment concordant } \\
\text { with guidelines }(N=28)\end{array}$} & \multirow[b]{2}{*}{$\begin{array}{c}\text { Total } \\
\mathrm{N}=36 \\
\end{array}$} \\
\hline & $\begin{array}{c}\text { Hypomania } \\
\mathrm{N}=3\end{array}$ & $\begin{array}{c}\text { Depression } \\
\qquad \mathbf{N}=3 \\
\end{array}$ & $\begin{array}{l}\text { Euthymia } \\
\qquad \mathrm{N}=2\end{array}$ & $\begin{array}{c}\text { Hypomania } \\
\mathrm{N}=14\end{array}$ & $\begin{array}{c}\text { Depression } \\
\mathrm{N}=4\end{array}$ & $\begin{array}{c}\text { Euthymia } \\
\mathrm{N}=10\end{array}$ & \\
\hline No psychotropics & 0 & 0 & 0 & 2 & 3 & 3 & $8(22.2 \%)$ \\
\hline Antidepressants without any mood stabilizer & 0 & 1 & 0 & 5 & - & 5 & $11(30.6 \%)$ \\
\hline Antidepressants in hypomania & 3 & - & - & 5 & - & - & $8(22.2 \%)$ \\
\hline Low dosage of treatment & 0 & 2 & 2 & 1 & 1 & 1 & $7(19.4 \%)$ \\
\hline $\begin{array}{l}\text { Other prescriptions of psychotropics, not } \\
\text { following guidelines }\end{array}$ & 0 & 0 & 0 & 1 & 0 & 1 & $2(5.6 \%)$ \\
\hline
\end{tabular}

treatment concordant, 1 = treatment non concordant). Previous hospitalizations, age at onset, current anxiety disorder, current substance use disorder, type of BD (type $\mathrm{I}=0$, type II $=1$ ) and nature of the current episode (depressive or euthymia $=0$; hypomanic $=1$ ) were entered as independent variables. Analysis was adjusted for sex and age. The nature of the episode was treated as a dichotomic variable, because of the small numbers. Actual age and age at onset were entered as continuous variables. Only the nature of the mood episode was independently associated with

Table 6 Number (\%) of subjects receiving at least one treatment following CANMAT guidelines by type and dosage of medication, by clinical and sociodemographic factors

\begin{tabular}{|c|c|c|c|c|c|}
\hline Variable & $\begin{array}{l}\text { At least one treatment concordant } \\
\text { with guidelines } \mathrm{N}(\%)\end{array}$ & $\mathrm{N}$ & Degree of freedom & $x^{2}$ & $\mathbf{P}$ \\
\hline \multicolumn{6}{|l|}{ Sex } \\
\hline Man & $26(66.7 \%)$ & 39 & 1 & 0.06 & 0.81 \\
\hline Woman & $51(68.9 \%)$ & 74 & & & \\
\hline \multicolumn{6}{|l|}{ Previous hospitalizations } \\
\hline Yes & $41(77.4 \%)$ & 53 & 1 & 3.91 & 0.05 \\
\hline No & $36(60.0 \%)$ & 60 & & & \\
\hline \multicolumn{6}{|l|}{ Type of bipolar disorder } \\
\hline Type I & $24(75.0 \%)$ & 32 & 1 & 0.97 & 0.32 \\
\hline Type ॥ & $53(65.4 \%)$ & 81 & & & \\
\hline \multicolumn{6}{|c|}{ Nature of the current mood episode } \\
\hline Hypomanic & $8(32.0 \%)$ & 25 & & & \\
\hline Depressive & $58(89.2 \%)$ & 65 & 2 & 32.7 & 0.001 \\
\hline Euthymic & $11(47.8 \%)$ & 23 & & & \\
\hline \multicolumn{6}{|c|}{ Comorbid anxiety disorder (current) } \\
\hline Present & $19(67.9 \%)$ & 28 & 1 & 0.001 & 0.97 \\
\hline Absent & $58(68.2 \%)$ & 85 & & & \\
\hline \multicolumn{6}{|c|}{ Comorbid substance use disorder (current) } \\
\hline Present & $15(53.6 \%)$ & 28 & 1 & 3.64 & 0.06 \\
\hline Absent & $62(72.9 \%)$ & 85 & & & \\
\hline Variable & Mean (SD) & $\mathbf{N}$ & & t-test & $P$ \\
\hline \multicolumn{6}{|l|}{ Age $($ mean $\pm S D)$} \\
\hline Treatment - concordant & $39.8 \pm 11.3$ & 77 & 1 & 1.58 & 0.18 \\
\hline Treatment - not concordant & $36.3 \pm 10.7$ & 36 & & & \\
\hline \multicolumn{6}{|l|}{ Age at onset (mean \pm SD) } \\
\hline Treatment - concordant & $22.4 \pm 8.0$ & 77 & 1 & 1.72 & 0.09 \\
\hline Treatment - not concordant & $25.5 \pm 9.0$ & 36 & & & \\
\hline
\end{tabular}


treatment not concordant to guidelines, with hypomania predicting poorer concordance (hypomania vs. depressive and euthymic: OR $(95 \% \mathrm{CI})=7.34$ ( 2.6 to 20.8$), \mathrm{p}<0.001)$.

\section{Discussion}

\section{Prevalence of psychotropic treatment}

Only $7 \%$ of the patients were treatment-free; antidepressants were the most prescribed treatment, especially in BD-II; lithium was administered to $62 \%$ of the bipolar I patients and only $18 \%$ of the bipolar II patients.

In comparing the findings of our study with the results from scientific literature, we noticed that the percentage of patients not given any psychotropics in our sample was similar to results taken from previous studies conducted within academic centres or teaching hospitals where percentages ranged from $2 \%$ to $8 \%$ [36-39] were noted. Verdoux et al. [40] found lower percentages (0.9\%) in hospital settings. Higher percentages (ranging between 16\% and $22 \%$ ) were found by Blanco et al. [41], examining data on a nationally representative group of visits to psychiatrists in an office-based practice within the US.

In our study, the global percentage of patients given lithium was $31 \%$, which is in the low range of percentages found in other studies, ranging from 30\% to 53\% [36-38,40-46]. This low rate is comparable with that observed in the United States where the percentage of bipolar patients prescribed with lithium has decreased from $50.9 \%$ in $1992-95$ to $30.1 \%$ in $1996-99$, based on the National Ambulatory Medical care survey [41]. By contrast, European countries show a higher percentage of lithium use compared with the United States [36-38,40,42-46]. Decrease in lithium use has paralleled the increased use of valproate (from $10.9 \%$ to $26.6 \%$ ) [41], and of second generation antipsychotics, (from 1.2\% to $17.0 \%$ in Blanco et al. [41]; see also Hayes et al. [47] Pillarella et al. [48]). The low percentage of lithium use found in our study may well reflect the general NorthAmerican trend. Our study actually indicates both second generation antipsychotic and valproate use rates as being relatively high ( $41.6 \%$ and $15.0 \%$, respectively), and this was consistent with the increasing trends in the use of such medications over the past decade.

In conducting our study, the type of BD appeared to be an important factor in predicting the use of lithium, with BD-I recording a much higher proportion of lithium users. This result is at odds with the STEP-BD data [46] which indicates a similar percentage of lithium users in BD-I and II (39.4\% and 35.7\%, respectively). On the other hand, Arvilommi et al. (2007) found that bipolar I patients were prescribed with mood stabilizers more often than bipolar II patients, which is consistent with our results, where the percentage of bipolar I patients taking at least one mood stabilizer or atypical antipsychotic in the therapeutic dosage was almost double than in bipolar II patients. This might not only reflect the CANMAT guidelines, but also the perceived lower degree of severity in BD-II and low consistency diagnosis. In our sample, about $20 \%$ of patients taking lithium had levels below the therapeutic range, which is consistent with the results of previous studies $[30,36]$.

The percentage of bipolar patients given antidepressants in our study $(62.8 \%)$ was similar to that found in similar studies conducted in North America. In the United States studies, corresponding percentages range from $40 \%$ to $74 \%[41,44-46,49,50]$. Studies by Blanco et al. [41] indicate a constant pattern in the use of antidepressants between 1992-1995 and 1996-1999 (45.8\% and $45.7 \%$, respectively). As expected, bipolar patients with depressive episodes seemed to be more likely to take antidepressants than other bipolar patients in our study. A similar trend was observed in the STEP-BD study [46].

Interestingly, there is also a transatlantic difference in antidepressant use, more frequent in the United States than in Europe [42] In UK studies, the percentage of antidepressant use varies from $14.3 \%$ to $38 \%$ [36-38,43], whereas in France, Verdoux [40] et al. found 34.2\% of bipolar patients prescribed with antidepressants.

In our sample, no bipolar patients were prescribed aripiprazole or ziprasidone, although CANMAT guidelines specifically recommended the two atypical antipsychotics in the treatment of BD-I since 2005 [16]. This can be due to the fact that Health Canada approved their use in the treatment of bipolar disorder only in 2009.

In our sampling, monotherapy with mood stabilizers was not a frequent approach, consistent with literature on the subject where only a minority of bipolar patients benefited from monotherapy treatment with lithium or other mood stabilizer (Ahmed and Anderson [36]: 23\%; Frangou et al. [43]: 23.8\%; Lloyd et al. [38]: 29\%; Ghaemi et al. [46]: 10.8\%; Verdoux et al. [40]: 14\%).

In recent years, polytherapy has been used more frequently in clinical practice [44,51]. Polytherapy is more commonly administered for depressed bipolar patients where monotherapy is much less efficacious [52], while guidelines for acute mania recommend monotherapy with mood stabilizers or antipsychotics. The high frequency of polytherapy noted in our study may well reflect the higher prevalence of depression; it also suggests that the severe state of patients referred to our tertiary care services are more likely to have comorbidities or disorders resistant to treatment.

\section{Concordance with treatment guidelines}

Treatment was congruent with guidelines in $68 \%$ of our sampling cases, when both type and dosage of the medications were considered. This percentage was quite high when compared with other studies. The larger spectrum 
of recommendations present in the CANMAT guidelines, compared with other guidelines, can partially explain this result [53].

Divergence from guidelines was mostly noted for patients suffering from hypomania, with $68 \%$ of hypomanic patients receiving non-concordant treatment to guidelines. In more than half of the cases, treatments not congruent with guidelines were due to inappropriate treatments with antidepressants; the remaining cases of non-concordance were due to the absence of psychotropic treatment or to inadequate dosage. Also noteworthy is that more than one-third of depressed bipolar II patients receiving treatment concordant with guidelines were prescribed antidepressants within monotherapy, which constitutes a third line recommendation under the CANMAT guidelines, and almost one third of all bipolar II patients were treated with antidepressant without any mood stabilizer.

The use of antidepressants for bipolar depression is still controversial. The major criticism regarding use of antidepressants in instances of bipolar depression is based on the risk of destabilizing mood, switching into mania or hypomania [54-56] or increasing the cycle frequency $[57,58]$. Such negative effects appear to be limited to certain classes of antidepressants [59-61]. Factors which appear to increase the risk of destabilization are: presence of mixed states $[62,63]$, subthreshold manic symptoms at baseline [64] and BD-I (versus BD-II) $[65,66]$, which suggests that different subpopulations may present different vulnerabilities to affective switching. In the STEP-BD study, approximately $15 \%$ of bipolar patients receiving long-term treatment with antidepressants developed a chronic irritable dysphoric state (ACID syndrome). The study indicated that the risk of developing ACID symptoms was linked to a previous history of antidepressant-induced affective switch, and to female gender [67]. Finally, the use of antidepressants may significantly increase the risk of suicidal ideation [68].

The efficacy of antidepressants in the acute treatment of bipolar depression is uncertain. The STEP-BD study showed similar efficacy comparing lithium or divalproex, alone or associated with an antidepressant [61]. In his meta-analysis, Gijsman et al. [69] suggested antidepressants as being effective in the short-term treatment of bipolar depression, but in a more recent meta-analysis, antidepressants were found not to be superior in any way to placebos in the acute treatment of bipolar depression [70]. Then again, Altshuler et al. [71] suggested the usefulness of maintaining antidepressant treatments within the subpopulation of patients who require both a mood stabilizer and an antidepressant to achieve complete remission from depressive episodes. Also controversial is the efficacy of longterm treatment with antidepressants in protecting patients from the recurrences of bipolar depression [55,72]. A metaanalysis of seven trials involving long-term treatments concluded that long-term adjunctive antidepressant treatments were not superior to mood stabilizers alone in protecting patients from recurrences, and that antidepressant monotherapies were associated with higher risks of mania or hypomania relapses [73].

Antidepressants administered within monotherapy are contraindicated for BD-I, because of the high risk of inducing mania or rapid cycling [54]. However, the risk/benefits may be different in BD-I and BD-II, and some studies suggest the efficacy and safety of antidepressant monotherapies in the treatment of BD-II [74-77]. CANMAT guidelines recommend antidepressants associated with mood stabilizers or atypical antipsychotics in the treatment of acute bipolar depression. Antidepressant monotherapy is only recommended as a third line treatment for BD-II, particularly for those with infrequent hypomanias [18].

Finally, though there is agreement on the different guidelines in the discontinuance of treatment with antidepressants during manic episodes, nevertheless they are at times prescribed in cases of acute mania in clinical practice $[33,78]$. Within our sampling, antidepressants were prescribed to certain bipolar II patients suffering from current hypomanic symptoms with "mixed" depressive symptoms or with rapid cycling. In both of these conditions, antidepressant treatment is specifically contraindicated [63].

Non-concordant treatment with guidelines observed in our sample can be explained in different ways. First, the diagnosis of $\mathrm{BD}$, especially type II, can be difficult at the onset of the disorder. In most cases, BD-II patients consult their doctor during the depressive phase, not during the hypomanic phase. Identifying the hypomanic episodes in BD-II can be difficult if appropriate questions are not asked, or if family members are not properly interviewed. Thus, before it is finally recognized, BD can be diagnosed as a recurrent depression over several years [79-82]. Some of the patients in our sample were misdiagnosed as having recurrent major depressive disorder. The second possible reason is that treatment with antidepressants, administered during episodes of depression or for purposes of preventing further episodes, is not suspended during a hypomanic phase, either because patients do not require medical intervention or because symptoms are not recognized. There is no consensus in the current guidelines on criteria governing time frames necessary to interrupt antidepressants [53], which can create confusion as to the appropriate discontinuation of antidepressants following depressive episodes. It is noteworthy that the CANMAT guidelines do not make explicit recommendations for BD-II hypomania, leaving some potential confusion for the reader whether recommendations for acute mania have to be adopted. Patients not adhering to treatment with mood stabilizers [83-85] is a third possible factor which explains the frequency of treatment with antidepressants, especially in monotherapy. Finally, there remains the possibility of general practitioners 
not following guidelines for lack of awareness, lack of agreement, or lack of familiarity.

Although the study focused on patients seen between the end of 2006 and beginning of 2009, we decided to use the 2009 guidelines rather than 2007, as some of the recommendations adopted in 2009 were already suggested in the previous version. For example, the possibility to use antidepressant monotherapy in bipolar II patients in depressive phase was already described in 2007, and more explicitly formulated in 2009. Other new recommendations adopted in the 2009 CANMAT version, which could potentially affect the percentage of concordance with guidelines in our sample, concerned with the use of quetiapine monotherapy as first line recommendation of BD-II depression and in BD-I maintenance; the use of divalproex monotherapy as second line recommendation in BD-I and BD-II depression; and the use of quetiapine in combination with lithium or divalproex in BD-I maintenance. In our sample, only two treatments would have been classified in a different way if we had adopted the 2007 guidelines: two BD-II depressive patients taking divalproex monotherapy would have been classified as "doesn't follow guidelines", instead of "second line treatment".

Our study, however, dealt with limitations. Our sample was relatively small, most notably as far as stratification was concerned. Also, we had to contend with a strong representation of depressed patients, which corresponds to a higher prevalence of depressive symptoms in the bipolar population.

\section{Conclusions}

In conclusion, the actual results support the efficacy of efforts made over the past years in attempting to communicate CANMAT guidelines. Our studies indicate a relatively high rate of concordance to guideline treatment by general practitioners. A significant caveat was identified, however, in the use of antidepressant medications, especially with respect to treatment of bipolar patients with hypomanic symptoms. Our study identifies the inappropriate use of antidepressants as one of the factors in outlining non-concordant treatment with guidelines. Although there is no evidence supporting the widespread use of antidepressants in $\mathrm{BD}$, and moreover, that there be evidence supporting the use of other agents in its treatment, antidepressants remain the most frequently prescribed class of psychotropic medications in this regard. In the absence of across-the-board consensus on the use of antidepressants in treating $\mathrm{BD}$, physicians have to individualize the risk/ benefits for each patient, and repeatedly reassess and reevaluate the need for antidepressants, which makes the treatment of bipolar patients particularly challenging. Given the high prevalence of depressive symptoms in bipolar patients, it appears that the symptoms, rather than the disorder, are often the target for treatment. Future research and intervention can change the current practice [86]. A recent study [87] has shown that educational programs were the best means of increasing the likelihood of general practitioners correctly assigning a subtype diagnosis in the treatment of $\mathrm{BD}$, and prescribing mood stabilizers instead of antidepressants.

\section{Abbreviations \\ AD: Antidepressant; AAP: Atypical antipsychotic; APA: American psychiatric association; BD: Bipolar disorder; CANMAT: Canadian network for mood and anxiety treatments; DSM-IVTR: Diagnostic standardized manual - revised; MS: Mood stabilizer; ROMHC: Royal Ottawa mental health centre; \\ SCID: Structured clinical interview for DSM-IV-TR; STEP-BD study: Systematic treatment enhancement program for bipolar disorder.}

\section{Competing interests}

Both authors declare that they have no competing interests.

\section{Authors' contributions}

SP contributed to design, analysis and interpretation of data and drafting the manuscript. Dr. JCB contributed to conception, design, interpretation of data and revising the manuscript for important intellectual content. Both authors have given final approval of the version to be published.

\section{Acknowledgement}

The authors gratefully acknowledge all members of the Assessment and Treatment Clinic team who made this study possible with their professional, dedicated and passionate work.

Received: 19 November 2012 Accepted: 5 August 2013

Published: 13 August 2013

\section{References}

1. Treuer T, Tohen M: Predicting the course and outcome of bipolar disorder: a review. Eur Psychiatry 2010, 25:328-333.

2. American Psychiatric Association: Practice guideline for the treatment of patients with bipolar disorder. Am J Psychiatry 1994, 151 (12 Suppl):1-36.

3. Bauer MS, Callahan AM, Jampala C, Petty F, Sajatovic M, Schaefer V, Wittlin B, Powell BJ: Clinical practice guidelines for bipolar disorder from the department of veterans affairs. J Clin Psychiatry 1999, 60:9-21.

4. Sachs GS, Printz DJ, Kahn DA, Carpenter D, Docherty JP: The expert consensus guideline series: medication treatment of bipolar disorder 2000. Postgrad Med 2000, 107:1-104.

5. Grunze H, Kasper S, Goodwin G, Bowden C, Baldwin D, Licht R, Vieta E, Möller HJ: World federation of societies of biological psychiatry task force on treatment guidelines for bipolar disorders. world federation of societies of biological psychiatry (WFSBP) guidelines for biological treatment of bipolar disorders. part I: treatment of bipolar depression. World J Biol Psychiatry 2002, 3:115-124.

6. Grunze H, Kasper S, Goodwin G, Bowden C, Baldwin D, Licht RW, Vieta E, Möller HJ: WFSBP task force on treatment guidelines for bipolar disorders. the world federation of societies of biological psychiatry (WFSBP) guidelines for the biological treatment of bipolar disorders, part II: treatment of mania. World J Biol Psychiatry 2003, 4:5-13.

7. Grunze H, Kasper S, Goodwin G, Bowden C, Möller HJ: WFSBP task force on treatment guidelines for bipolar disorders. the world federation of societies of biological psychiatry (WFSBP) guidelines for the biological treatment of bipolar disorders, part III: maintenance treatment. World J Biol Psychiatry 2004, 5:120-135.

8. Suppes T, Dennehy EB, Swann AC, Bowden CL, Calabrese JR, Hirschfeld RM, Keck PE Jr, Sachs GS, Crismon ML, Toprac MG, Shon SP: Texas consensus conference panel on medication treatment of bipolar disorder. report of the Texas consensus conference panel on medication treatment of bipolar disorder 2000. J Clin Psychiatry 2002, 63:288-299.

9. Goodwin GM: Consensus rroup of the British association for psychopharmacology. evidence-based guidelines for treating bipolar disorder: recommendations from the British association for psychopharmacology. J Psychopharmacol 2003, 17:149-173. 
10. American Psychiatric Association: Practice guideline for the treatment of patients with bipolar disorder (revision). Am J Psychiatry 2002, 159(4 Suppl):1-50.

11. Keck P, Perlis R, Otto M: The expert consensus guideline series : medication treatment of bipolar disorder. Postgrad Med 2004, 2004:1-120.

12. Suppes $T$, Dennehy EB, Hirschfeld RM, Altshuler LL, Bowden CL, Calabrese JR, Crismon ML, Ketter TA, Sachs GS, Swann AC: Texas consensus conference panel on medication treatment of bipolar disorder. the Texas implementation of medication algorithms: update to the algorithms for treatment of bipolar I disorder. J Clin Psychiatry 2005, 66:870-886.

13. Grunze H, Vieta E, Goodwin GM, Bowden C, Licht RW, Moller HJ, Kasper S: The world federation of societies of biological psychiatry (WFSBP) guidelines for the biological treatment of bipolar disorders: update 2009 on the treatment of acute mania. World J Biol Psychiatry 2009, 10:85-116.

14. Grunze H, Vieta E, Goodwin GM, Licht RW, Möller HJ, Kasper S: WFSBP task force on treatment guidelines for bipolar disorders. the world federation of societies of biological psychiatry (WFSBP) guidelines for the biological treatment of bipolar disorders: update 2010 on the treatment of acute bipolar depression. World J Biol Psychiatry 2010, 11:81-109.

15. Canadian Network for Mood and Anxiety Treatments (CANMAT): The treatment of bipolar disorder: review of the literature, guidelines, and options. Can J Psychiatry 1997, 42(Suppl 2):67S-100S

16. Yatham LN, Kennedy SH, O'Donovan C, Parikh S, MacQueen G, Mclntyre R, Sharma V, Silverstone P, Alda M, Baruch P, Beaulieu S, Daigneault A, Milev R, Young LT, Ravindran A, Schaffer A, Connolly M, Gorman CP: Canadian network for mood and anxiety treatments. Canadian network for mood and anxiety treatments (CANMAT) guidelines for the management of patients with bipolar disorder: consensus and controversies. Bipolar Disord 2005, 7(Suppl 3):5-69.

17. Yatham LN, Kennedy SH, O'Donovan C, Parikh SV, MacQueen G, Mclntyre RS, Sharma V, Beaulieu S, Guidelines Group, CANMAT: Canadian network for mood and anxiety treatments (CANMAT) guidelines for the management of patients with bipolar disorder: update 2007. Bipolar Disord 2006, 8:721-739.

18. Yatham LN, Kennedy SH, Schaffer A, Parikh SV, Beaulieu S, O'Donovan C, MacQueen G, McIntyre RS, Sharma V, Ravindran A, Young LT, Young AH, Alda M, Milev R, Vieta E, Calabrese JR, Berk M, Ha K, Kapczinski F: Canadian network for mood and anxiety treatments (CANMAT) and international society for bipolar disorders (ISBD) collaborative update of CANMAT guidelines for the management of patients with bipolar disorder: update 2009. Bipolar Disord 2009, 11:225-255

19. Suppes T, Rush AJ, Dennehy EB, Crismon ML, Kashner TM, Toprac MG, Carmody TJ, Brown ES, Biggs MM, Shores-Wilson K, Witte BP, Trivedi MH, Miller AL, Altshuler KZ, Shon SP: Texas medication algorithm project. Texas medication algorithm project, phase 3 (TMAP-3): clinical results for patients with a history of mania. J Clin Psychiatry 2003, 64:370-382.

20. Dennehy EB, Suppes T, Rush AJ, Miller AL, Trivedi MH, Crismon ML, Carmody TJ, Kashner TM: Does provider adherence to a treatment guideline change clinical outcomes for patients with bipolar disorder? results from the Texas medication algorithm project. Psychol Med 2005, 35:1695-1706

21. Perlis RH: Use of treatment guidelines in clinical decision making in bipolar disorder: a pilot survey of clinicians. Curr Med Res Opin 2007, 23:467-475

22. Samalin L, Guillaume S, Auclair C, Llorca PM: Adherence to guidelines by French psychiatrists in their real world of clinical practice. $J$ Nerv Ment Dis 2011, 199:239-243.

23. Divac N, Marić NP, Damjanović A, Jovanović AA, Jasović-Gasić M, Prostran M: Use or underuse of therapeutic guidelines in psychiatry? Psychiatr Danub 2009, 21:224-229

24. Lim PZ, Tunis SL, Edell WS, Jensik SE, Tohen M: Medication prescribing patterns for patients with bipolar I disorder in hospital settings: adherence to published practice guidelines. Bipolar Disord 2001, 3:165-173.

25. Arvilommi P, Suominen KS, Mantere OK, Leppämäki S, Valtonen H, Isometsä ET: Adequacy of treatment received by diagnosed and undiagnosed patients with bipolar I and II disorders. J Clin Psychiatry 2007, 68:102-110.

26. Altınbaş K, Smith D, Oral ET: Adherence to Turkish psychiatric association guideline for bipolar depression treatment in a specialized mood disorders outpatient unit. Psychiatr Danub 2011, 23:189-193.

27. Smith TE, Levine SB, Hampel J: A successful effort to improve adherence to treatment guidelines for bipolar disorder. Harv Rev Psychiatry 2008, $16: 210-213$
28. Bauer MS, Biswas K, Kilbourne AM: Enhancing multiyear guideline concordance for bipolar disorder through collaborative care. Am J Psychiatry 2009, 166:1244-1250

29. Dennehy EB, Bauer MS, Perlis RH, Kogan JN, Sachs GS: Concordance with treatment guidelines for bipolar disorder: data from the systematic treatment enhancement program for bipolar disorder. Psychopharmacol Bull 2007, 40:72-84.

30. Unützer J, Simon G, Pabiniak C, Bond K, Katon W: The use of administrative data to assess quality of care for bipolar disorder in a large staff model HMO. Gen Hosp Psychiatry 2000, 22:1-10.

31. Simon NM, Otto MW, Weiss RD, Bauer MS, Miyahara S, Wisniewski SR, Thase ME, Kogan J, Frank E, Nierenberg AA, Calabrese JR, Sachs GS, Pollack MH: STEP-BD investigators. pharmacotherapy for bipolar disorder and comorbid conditions: baseline data from STEP-BD. J Clin Psychopharmacol 2004, 24:512-520.

32. Kilbourne AM, Bauer MS, Han X, Haas GL, Elder P, Good CB, Shad M, Conigliaro J, Pincus $\mathrm{H}$ : Racial differences in the treatment of veterans with bipolar disorder. Psychiatr Serv 2005, 56:1549-1555.

33. Farrelly N, Dibben $\mathrm{C}$, Hunt N: Current management of bipolar affective disorder: is it reflective of the BAP guidelines? J Psychopharmacol 2006, 20:128-131.

34. Busch $A B$, Huskamp HA, Landrum MB: Quality of care in a Medicaid population with bipolar I disorder. Psychiatr Serv 2007, 58:848-854.

35. First MB, Spitzer RL, Gibbon M, Williams JBW: Structured Clinical Interview for DSM-IV and DSM-IV-TR Axis I Disorders, Clinician Version (SCID-CV). Arlington, VA: American Psychiatric Publishing, Inc.; 2002.

36. Ahmed Z, Anderson IM: Treatment of bipolar affective disorder in clinical practice. J Psychopharmacol 2001, 15:55-57.

37. Anderson IM, Haddad PM, Chaudhry I: Changes in pharmacological treatment for bipolar disorder over time in Manchester: a comparison with Lloyd et al. (2003). J Psychopharmacol 2004, 18:441-444.

38. Lloyd AJ, Harrison CL, Ferrier IN, Young AH: The pharmacological treatment of bipolar affective disorder: practice is improving but could still be better. J Psychopharmacol 2003, 17:230-233.

39. Busch AB, Frank RG, Sachs G, Normand SL: Bipolar-I patient characteristics associated with differences in antimanic medication prescribing. Psychopharmacol Bull 2009, 42:35-49.

40. Verdoux H, Gonzales B, Takei N, Bourgeois M: A survey of prescribing practice of antipsychotic maintenance treatment for manic-depressive outpatients. J Affect Disord 1996, 38:81-87.

41. Blanco C, Laje G, Olfson M, Marcus SC, Pincus HA: Trends in the treatment of bipolar disorder by outpatient psychiatrists. Am J Psychiatry 2002, 159:1005-1010.

42. Post RM, Leverich GS, Altshuler LL, Frye MA, Suppes T, Keck PE, McElroy SL, Nolen WA, Kupka R, Grunze H, Walden J, Rowe M: Differential clinical characteristics, medication usage, and treatment response of bipolar disorder in the US versus The Netherlands and Germany. Int Clin Psychopharmacol 2011, 26:96-106.

43. Frangou S, Raymont V, Bettany D: The Maudsley bipolar disorder project. a survey of psychotropic prescribing patterns in bipolar I disorder. Bipolar Disord 2002, 4:378-385.

44. Levine J, Chengappa KN, Brar JS, Gershon S, Yablonsky E, Stapf D, Kupfer DJ: Psychotropic drug prescription patterns among patients with bipolar I disorder. Bipolar Disord 2000, 2:120-130.

45. Depp C, Ojeda VD, Mastin W, Unützer J, Gilmer TP: Trends in use of antipsychotics and mood stabilizers among Medicaid beneficiaries with bipolar disorder, 2001-2004. Psychiatr Serv 2008, 59:1169-1174.

46. Ghaemi SN, Hsu DJ, Thase ME, Wisniewski SR, Nierenberg AA, Miyahara S, Sachs G: Pharmacological treatment patterns at study entry for the first 500 STEP-BD participants. Psychiatr Serv 2006, 57:660-665.

47. Hayes J, Prah P, Nazareth I, King M, Walters K, Petersen I, Osborn D: Prescribing trends in bipolar disorder: cohort study in the United Kingdom THIN primary care database 1995-2009. PLoS One 2011, 6:e28725.

48. Pillarella J, Higashi A, Alexander GC, Conti R: Trends in use of secondgeneration antipsychotics for treatment of bipolar disorder in the United States, 1998-2009. Psychiatr Serv 2012, 63:83-86.

49. Russo P, Smith MW, Dirani R, Namjoshi M, Tohen M: Pharmacotherapy patterns in the treatment of bipolar disorder. Bipolar Disord 2002, 4:366-377.

50. Baldessarini RJ, Leahy L, Arcona S, Gause D, Zhang W, Hennen J: Patterns of psychotropic drug prescription for U.S. patients with diagnoses of bipolar disorders. Psychiatr Serv 2007, 58:85-91. 
51. Mojtabai R, Olfson M: National trends in psychotropic medication polypharmacy in office-based psychiatry. Arch Gen Psychiatry 2010, 67:26-36.

52. Tamayo JM, Zarate CA Jr, Vieta E, Vázquez G, Tohen M: Level of response and safety of pharmacological monotherapy in the treatment of acute bipolar I disorder phases: a systematic review and meta-analysis. Int J Neuropsychopharmacol 2010, 13:813-832.

53. Nivoli AM, Colom F, Murru A, Pacchiarotti I, Castro-Loli P, González-Pinto A, Fountoulakis KN, Vieta E: New treatment guidelines for acute bipolar depression: a systematic review. J Affect Disord 2011, 129:14-26.

54. Tondo L, Vázquez G, Baldessarini RJ: Mania associated with antidepressant treatment: comprehensive meta-analytic review. Acta Psychiatr Scand 2010, 121:404-414.

55. Baldessarini RJ, Vieta E, Calabrese JR, Tohen M, Bowden CL: Bipolar depression: overview and commentary. Harv Rev Psychiatry 2010, 18:143-157.

56. Undurraga J, Baldessarini RJ, Valentí M, Pacchiarotti I, Tondo L, Vázquez G, Vieta E: Bipolar depression: clinical correlates of receiving antidepressants. J Affect Disord 2012, 139:89-93.

57. Schneck CD, Miklowitz DJ, Miyahara S, Araga M, Wisniewski S, Gyulai L, Allen $\mathrm{MH}$, Thase ME, Sachs GS: The prospective course of rapid-cycling bipolar disorder: findings from the STEP-BD. Am J Psychiatry 2008, 165:370-377.

58. Datta V, Cleare AJ: Recent advances in bipolar disorder pharmacotherapy: focus on bipolar depression and rapid cycling. Expert Rev Clin Pharmacol 2009, 2:423-434.

59. Nemeroff CB, Evans DL, Gyulai L, Sachs GS, Bowden CL, Gergel IP, Oakes R, Pitts CD: Double-blind, placebo-controlled comparison of imipramine and paroxetine in the treatment of bipolar depression. Am J Psychiatry 2001, 158:906-912

60. Post RM, Altshuler LL, Leverich GS, Frye MA, Nolen WA, Kupka RW, Suppes T, McElroy S, Keck PE, Denicoff KD, Grunze H, Walden J, Kitchen CM, Mintz J: Mood switch in bipolar depression: comparison of adjunctive venlafaxine, bupropion and sertraline. Br J Psychiatry 2006, 189:124-131.

61. Sachs GS, Nierenberg AA, Calabrese JR, Marangell LB, Wisniewski SR, Gyulai L, Friedman ES, Bowden CL, Fossey MD, Ostacher MJ, Ketter TA, Patel J, Hauser P, Rapport D, Martinez JM, Allen MH, Miklowitz DJ, Otto MW Dennehy EB, Thase ME: Effectiveness of adjunctive antidepressant treatment for bipolar depression. N Engl J Med 2007, 356:1711-1722.

62. Goldberg JF, Perlis RH, Ghaemi SN, Calabrese JR, Bowden CL, Wisniewski S, Miklowitz DJ, Sachs GS, Thase ME: Adjunctive antidepressant use and symptomatic recovery among bipolar depressed patients with concomitant manic symptoms: findings from the STEP-BD. Am J Psychiatry 2007, 164:1348-1355.

63. Fountoulakis KN, Kasper S, Andreassen O, Blier P, Okasha A, Severus E, Versiani M, Tandon R, Möller HJ, Vieta E: Efficacy of pharmacotherapy in bipolar disorder: a report by the WPA section on pharmacopsychiatry. Eur Arch Psychiatry Clin Neurosci 2012, 262(Suppl 1):1-48.

64. Frye MA, Helleman G, McElroy SL, Altshuler LL, Black DO, Keck PE Jr, Nolen WA, Kupka R, Leverich GS, Grunze H, Mintz J, Post RM, Suppes T: Correlates of treatment-emergent mania associated with antidepressant treatment in bipolar depression. Am J Psychiatry 2009, 166:164-172.

65. Altshuler LL, Suppes T, Black DO, Nolen WA, Leverich G, Keck PE Jr, Frye MA, Kupka R, McElroy SL, Grunze H, Kitchen CM, Post R: Lower switch rate in depressed patients with bipolar II than bipolar I disorder treated adjunctively with second-generation antidepressants. Am J Psychiatry 2006, 163:313-315.

66. Bond DJ, Noronha MM, Kauer-Sant'Anna M, Lam RW, Yatham LN: Antidepressant-associated mood elevations in bipolar II disorder compared with bipolar I disorder and major depressive disorder: a systematic review and meta-analysis. J Clin Psychiatry 2008, 69:1589-1601.

67. El-Mallakh RS, Ghaemi SN, Sagduyu K, Thase ME, Wisniewski SR, Nierenberg AA, Zhang HW, Pardo TA, Sachs G: STEP-BD investigators. antidepressantassociated chronic irritable dysphoria (ACID) in STEP-BD patients. J Affect Disord 2008, 111:372-377.

68. Goldberg JF, Garno JL, Portera L, Leon AC, Kocsis JH, Whiteside JE: Correlates of suicidal ideation in dysphoric mania. J Affect Disord 1999 $56: 75-81$.

69. Gijsman HJ, Geddes JR, Rendell JM, Nolen WA, Goodwin GM: Antidepressants for bipolar depression: a systematic review of randomized, controlled trials. Am J Psychiatry 2004, 161:1537-1547.

70. Sidor MM, Macqueen GM: Antidepressants for the acute treatment of bipolar depression: a systematic review and meta-analysis. J Clin Psychiatry 2011, 72:156-167.
71. Altshuler LL, Post RM, Hellemann G, Leverich GS, Nolen WA, Frye MA, Keck PE Jr, Kupka RW, Grunze H, McElroy SL, Sugar CA, Suppes T: Impact of antidepressant continuation after acute positive or partial treatment response for bipolar depression: a blinded, randomized study. J Clin Psychiatry 2009, 70:450-457.

72. Altshuler L, Suppes T, Black D, Nolen WA, Keck PE Jr, Frye MA, McElroy S, Kupka R, Grunze H, Walden J, Leverich G, Denicoff K, Luckenbaugh D, Post $R$ : Impact of antidepressant discontinuation after acute bipolar depression remission on rates of depressive relapse at 1-year follow-up. Am J Psychiatry 2003, 160:1252-1262.

73. Ghaemi SN, Wingo AP, Filkowski MA, Baldessarini RJ: Long-term antidepressant treatment in bipolar disorder: meta-analyses of benefits and risks. Acta Psychiatr Scand 2008, 118:347-356.

74. Agosti V, Stewart JW: Efficacy and safety of antidepressant monotherapy in the treatment of bipolar-II depression. Int Clin Psychopharmacol 2007, 22:309-311.

75. Amsterdam JD, Shults J: Comparison of short-term venlafaxine versus lithium monotherapy for bipolar II major depressive episode: a randomized open-label study. J Clin Psychopharmacol 2008, 28:171-181.

76. Amsterdam JD, Wang CH, Shwarz M, Shults J: Venlafaxine versus lithium monotherapy of rapid and non-rapid cycling patients with bipolar II major depressive episode: a randomized, parallel group, open-label trial. $J$ Affect Disord 2009, 112:219-230.

77. Swartz HA, Thase ME: Pharmacotherapy for the treatment of acute bipolar II depression: current evidence. J Clin Psychiatry 2011, 72:356-366.

78. Rosa AR, Cruz N, Franco C, Haro JM, Bertsch J, Reed C, Aerre TF, SanchezMoreno J, Vieta E: Why do clinicians maintain antidepressants in some patients with acute mania? hints from the European mania and bipolar longitudinal evaluation of medication (EMBLEM), a large naturalistic study. J Clin Psychiatry 2010, 71:1000-1006.

79. Ghaemi SN, Sachs GS, Chiou AM, Pandurangi AK, Goodwin K: Is bipolar disorder still underdiagnosed? are antidepressants overutilized? J Affect Disord 1999, 52:135-144.

80. Frye MA, Calabrese JR, Reed ML, Wagner KD, Lewis L, McNulty J, Hirschfeld RM: Use of health care services among persons who screen positive for bipolar disorder. Psychiatr Serv 2005, 56:1529-1533.

81. Correa R, Akiskal H, Gilmer W, Nierenberg AA, Trivedi M, Zisook S: Is unrecognized bipolar disorder a frequent contributor to apparent treatment resistant depression? J Affect Disord 2010, 127:10-18.

82. Angst J, Azorin JM, Bowden CL, Perugi G, Vieta E, Gamma A, Young AH, BRIDGE Study Group: Prevalence and characteristics of undiagnosed bipolar disorders in patients with a major depressive episode: the BRIDGE study. Arch Gen Psychiatry 2011, 68:791-798.

83. Maj M, Pirozzi R, Magliano L, Bartoli L: Long-term outcome of lithium prophylaxis in bipolar disorder: a 5-year prospective study of 402 patients at a lithium clinic. Am J Psychiatry 1998, 155:30-35.

84. Baldessarini RJ, Perry R, Pike J: Factors associated with treatment nonadherence among US bipolar disorder patients. Hum Psychopharmacol 2008, 23:95-105.

85. Thase ME: Strategies for increasing treatment adherence in bipolar disorder. J Clin Psychiatry 2012, 73:e08.

86. Giese AA: Closing the gap between guidelines for bipolar disorder treatment and clinical practice. Am J Psychiatry 2009, 166:1205-1206.

87. Rouillon F, Gasquet I, Garay RP, Lancrenon S: Impact of an educational program on the management of bipolar disorder in primary care. Bipolar Disord 2011, 13:318-322.

\section{doi:10.1186/1471-244X-13-211}

Cite this article as: Paterniti and Bisserbe: Pharmacotherapy for bipolar disorder and concordance with treatment guidelines: survey of a general population sample referred to a tertiary care service. BMC Psychiatry 2013 13:211. 